\title{
ANAL ATRESIA : EFFECT OF SMOKING AND DRINKING HABITS DURING PREGNANCY
}

\author{
Ping Yuan, ${ }^{1,2}$ Isao OKaZAKI, ${ }^{2}$ and Yoshikazu Kuroki ${ }^{1, *}$ \\ ${ }^{1}$ Division of Medical Genetics, Kanagawa Children's Medical Center, \\ 2-138-4 Mutsukawa, Minami-ku, Yokohama 232, Japan \\ ${ }^{2}$ Department of Community Health, Division of Community Health and \\ Environmental Medicine, School of Medicine, Tokai University, \\ Bohseidai, Isehara, Kanagawa 259-11, Japan
}

\begin{abstract}
Summary Using data compiled from 216,707 births from the population-based Kanagawa Birth Defects Monitoring Program (KAMP), we conducted a case-control study to evaluate the effect of maternal smoking and/or drinking during pregnancy on the risk of infants' anal atresia in 1989-1994. The frequency of maternal smoking (including passive smoking) and/or maternal drinking during pregnancy among 84 infants with anal atresia was compared with 174 matched controls. The 84 anal atresias include 49 cases of isolated anal atresia and 35 cases of syndromal anal atresia. Our findings suggest that maternal drinking during early pregnancy is associated with an increased risk of isolated anal atresia $(\mathrm{OR}=4.8,95 \% \mathrm{CI} 1.2$ to $19.1, \mathrm{p}<0.05)$. A slightly increased trend was also observed in the association of maternal smoking during pregnancy with both in the pooled groups of anal atresia ( $O R=1.4,95 \%$ CI 0.5 to 3.6). Key Words anal atresia, drinking, smoking, case-control study, birth defects monitoring
\end{abstract}

\section{INTRODUCTION}

Anal atresia is a common congenital anomaly in the newborn babies observed at a rate of 1 in 2,500 to 5,000 live births (Anderson and Reed, 1954; Stephens and Smith, 1971; Nagashima, 1994). The majority of reported cases of anal atresia were not familial (Oeconomopoulos, 1961; Stephens and Smith, 1971), while others have described that anal atresia could be a hereditary disease. It has been suggested that the anomaly could be caused by an autosomal dominant, autosomal recessive or sex-linked gene (Weinstein, 1965; Saeki and Akiyama, 1978; Schwoebel

Received December 2, 1994; Revised version accepted September 27, 1995.

* To whom correspondence should be addressed. 
et al., 1984; Nagashima, 1994). However, the clinician has an impression that smoking and/or drinking habits of patients' mothers during pregnancy could elevate the risk of anal atresia.

Anal atresia can be divided into two groups: one accompanied by multiple malformations with or without recognized chromosomal abnormalities, and the other having no other malformations. The former is called syndromal anal atresia, and the latter is called isolated anal atresia by the present authors. Isolated anal atresia has been considered not due to primary chromosomal abnormalities of germ cell, but rather is caused by several intrauterine environmental factors that affect growth and development of embryos. Of these environmental factors, tobacco and alcohol have been reported to influence the development of fetus. Therefore, we studied the effect of smoking and drinking during pregnancy on isolated anal atresia and syndromal anal atresia in order to clarify their etiological implications of an intrauterine environment.

We report here the results of a population-based case-control study of anal atresia and maternal lifestyles, such as smoking (either active or passive) and drinking habits during pregnancy, using the data from the KAMP.

\section{SUBJECTS AND METHODS}

Ninety-four cases with anal atresia were ascertained from 216, 707 single births, including stillbirths, born in Kanagawa Prefecture, during the period between April 1989 and March 1994. Sixty cases were males, 28 were females, and 6 were undermined. Fifty-three cases $(56.4 \%)$ had anal atresia without other malformations (isolated anal atresia). Seven cases with recognized chromosomal syndromes and 34 cases with multiple malformations combined representing syndromal anal atresia $(43.6 \%$ ). In both groups, 14 cases were stillborn, and 6 died within 7 days after birth; 16 cases were diagnosed prenatally.

In the KAMP, all malformed cases are as well as all multiple births are registered with two consecutive normal control infants. Therefore, controls are twice in number of malformed cases. In this study, two controls for each anal atresia case were selected from the control populations. They were matched in respect to maternal age groups (5-years interval), sex, parity, and season of birth. Parental smoking habits, periods of smoking (first, second, and third trimester), and the amount of cigarettes smoked were studied. Maternal drinking habit, periods of drinking during pregnancies and the amount of alcohol consumption were also studied. Ten cases and 14 controls were excluded from this study because of unreliable data concerning smoking and alcohol consumption. Therefore, final number of cases and controls was 84 and 174, respectively.

Parental occupations were not considered in this study because $97 \%$ of the parents of both the cases and controls had not been reported about any exposure of specific chemicals or physical factors at work. 
Statistical analysis was performed using High-quality Analysis Libraries for Business and Academic Users" [HALBAU] program. The criterion of significance was taken as $\mathrm{p}<0.05$. Association between anal atresia and smoking and/or alcohol was estimated by odds ratios (OR) with $95 \%$ confidence intervals.

\section{RESULTS}

Some vital data of anal atresia are shown in Table 1. The gestational age and weight at birth were lower than those in the KAMP $(p<0.001, p<0.001)$.

Table 2 shows the comparison of background data of the mothers of infants with anal atresia with the mothers of normal infants. The history of previous

Table 1. Vital information of the infants with anal atresia, Kanagawa, Japan, 1989-1994.

\begin{tabular}{lccc}
\hline $\begin{array}{l}\text { Characteristics of infants } \\
\text { with anal atresia }\end{array}$ & $\begin{array}{c}\text { Isolated } \\
n=49(\%)\end{array}$ & $\begin{array}{c}\text { Syndromal } \\
n=35(\%)\end{array}$ & $\begin{array}{c}\text { Total } \\
\mathrm{n}=84(\%)\end{array}$ \\
\hline Mean maternal age $(\mathrm{yr})^{\mathrm{a}}$ & $28.7 \pm 4.7$ & $29.6 \pm 5.2$ & $29.1 \pm 4.9$ \\
Mean paternal age $(\mathrm{yr})^{\mathrm{b}}$ & $32.7 \pm 5.4$ & $32.1 \pm 5.6$ & $32.1 \pm 5.6$ \\
Sex & $38(77.6)$ & $18(54.3)$ & $57(67.9)$ \\
$\quad$ male & $11(22.4)$ & $12(34.3)$ & $23(27.3)$ \\
$\quad$ fermale & 0 & $4(11.4)$ & $4(4.8)$ \\
$\quad$ undetermined & $23(46.9)$ & $17(48.6)$ & $40(47.6)$ \\
1st live births & $26(53.1)$ & $18(51.4)$ & $44(52.4)$ \\
2nd or over live births & $47(95.9)$ & $21(60.0)$ & $68(81.0)$ \\
Live births & 0 & $5(14.3)$ & $5(6.0)$ \\
Death within 7 days after birth & $2(4.1)$ & $9(25.7)$ & $11(13.1)$ \\
Stillborns & $37.9 \pm 2.9$ & $34.8 \pm 4.3$ & $36.6 \pm 3.9$ \\
Mean gestational age $(\mathrm{w}) \mathrm{c}$ & $2,851.9 \pm 615.5$ & $1,930.9 \pm 760.6$ & $2,468.2 \pm 817.5$ \\
Mean birth weight $(\mathrm{g})^{\mathrm{d}}$ & & & \\
Period of diagnosis & $2(4.1)$ & $13(37.1)$ & $15(17.9)$ \\
$\quad$ prenatal & $47(95.9)$ & $22(62.9)$ & $69(82.1)$ \\
postnatal & & & - \\
Anal atresia found in & - & $18(51.4)$ & - \\
known syndromes & - & $17(48.6)$ & - \\
unspecified MCA* & & - & \\
\hline
\end{tabular}

a It showed no difference from those in the KAMP population (mean 29.7 years).

b It showed no difference from those in the KAMP population (mean 32.8 years).

e It was shorter than the mean gestational week in KAMP $(38 w \pm 1 w)$ during the same period $(\mathrm{p}<0.001)$.

d It was lower than the mean birth weight in $\operatorname{KAMP}(3,070 \mathrm{~g} \pm 437 \mathrm{~g})$ during the same period $(\mathrm{p}<0.001)$.

* Multiple congenital anomalies. 
births with malformations was more common in the cases $(3.6 \%)$ than controls (none), although this difference was not statistically significant.

Numbers of infant with anal atresia by smoking and/or drinking of the parents are shown in Table 3 . About $10.7 \%$ of the mothers of infants with anal atresia and $8.0 \%$ of the mothers of controls were smokers without drinking, and the rate of drinker without smoking during pregnancy was $13.1 \%$ and $8.5 \%$, respectively. In isolated anal atresia, mothers who smoked or drank were more numerous $(12.2 \%$, $14.3 \%)$, compared with the controls $(8.0 \%, 8.5 \%)$. However, these differences were not statistically significant. The prevalence of mothers habit of both smoking and drinking during pregnancy was similar between cases and controls $(2.4 \%$ vs. $23 \%)$.

Table 2. Comparison of the background between the mothers of infants with anal atresia and the mothers of normal control infants.

\begin{tabular}{lccc}
\hline Characteristics & $\begin{array}{c}\text { Anal atresia } \\
\mathrm{n}=84(\%)\end{array}$ & $\begin{array}{c}\text { Controls } \\
\mathrm{n}=176(\%)\end{array}$ & $\begin{array}{c}\text { OR }^{\mathrm{a}} \\
\left(95 \% \mathrm{Cl}^{\mathrm{b}}\right)\end{array}$ \\
\hline $\begin{array}{l}\text { Consanguineous marriage } \\
\text { History of }\end{array}$ & 0 & 0 & \\
$\quad$ spontaneous abortions & $8(9.5)$ & $26(14.8)$ & $0.6(0.2-1.5)$ \\
$\quad$ stillborns & 0 & $4(2.3)$ & - \\
$\quad$ delivering births with malformations & $3(3.6)$ & 0 & - \\
$\quad$ exposure to high level radiation & 0 & $1(0.6)$ & - \\
$\begin{array}{l}\text { During early pregnancy } \\
\text { any abnormality }\end{array}$ & $6(7.1)$ & $18(10.2)$ & $0.7(0.2-1.9)$ \\
$\quad$ drugs used & $10(11.9)$ & $18(10.2)$ & $1.2(0.5-2.9)$ \\
exposure to radiation & $1(1.2)$ & $3(1.7)$ & $0.7(0-7.7)$ \\
\hline
\end{tabular}

a Odds ratio. b $95 \%$ confidence intervals.

Table 3. Number of cases of anal atresia by smoking and/or drinking parents.

\begin{tabular}{ccccccc}
\hline \multicolumn{2}{c}{ Smoking } & Mother's & $\begin{array}{c}\text { Isolated } \\
\mathrm{n}=49 \\
(\%)\end{array}$ & $\begin{array}{c}\text { Syndromal } \\
\mathrm{n=35} \\
(\%)\end{array}$ & $\begin{array}{c}\text { Total } \\
\mathrm{n=84} \\
(\%)\end{array}$ & $\begin{array}{c}\text { Controls } \\
\mathrm{n}=176 \\
(\%)\end{array}$ \\
\hline- & - & - & $17(34.7)$ & $14(40.0)$ & $31(36.9)$ & $80(45.4)$ \\
+ & - & - & 0 & 0 & 0 & $1(0.6)$ \\
- & - & + & $6(12.2)^{*}$ & $1(2.9)$ & $7(8.3)$ & $5(2.8)$ \\
+ & - & + & 0 & 0 & 0 & $1(0.6)$ \\
- & + & - & $19(38.8)$ & $12(34.2)$ & $31(36.9)$ & $63(35.8)$ \\
+ & + & - & $6(12.2)$ & $3(8.6)$ & $9(10.7)$ & $13(7.4)$ \\
- & + & + & $1(2.1)$ & $3(8.6)$ & $4(4.8)$ & $10(5.7)$ \\
+ & + & + & 0 & $2(5.7)$ & $2(2.4)$ & $3(1.7)$ \\
\hline
\end{tabular}

* Statistically significant $(\mathrm{p}<0.05)$. 
There were no cases and only 1 control mother who smoked during pregnancy but whose husband did not smoke. The mothers who drank during pregnancy but whose husband did not smoke were more numerous in the cases $(8.3 \%)$ than in controls $(2.8 \%)$. Such tendency was evident especially among isolated anal atresia group $(12.2 \%)(\mathrm{p}<0.05)$, showing an odds ratio of $4.8(95 \%$ confidence intervals, 1.2-19.1). The frequency of passive smoking, with or without drinking during pregnancy, was $36.9 \%$ in the cases and $35.8 \%$ in the controls.

Smoker mothers during pregnancy with smoker husband $(10.7 \%$, as well as smoking and drinking with smoker husband $(2.4 \%)$ were more prevalent among the cases compared to the controls $(7.4 \%, 1.7 \%)$. The OR was 1.4 and 1.4 , respectively. The result was not statistically significant. There was no difference about the frequency of both drinking habits and paternal smoking between the cases and controls.

Most mothers smoked less than 10 pieces of cigarettes per day in both cases and controls. Among the mothers who had drinking habit, $92.9 \%$ of cases and $100.0 \%$ of controls drunk small amounts. About a half of smoking husbands smoked 10-19 pieces of cigarettes per day both in cases and controls. Neither the levels of maternal smoking and alcohol consumption per day during pregnancy nor the level of husbands' smoking per day differed between cases and controls. The numbers of mothers who smoked throughout pregnancy ( $>28$ th week) were slightly more in cases than in controls.

\section{DISCUSSION}

Congenital anomalies are the most prevalent cause of infant deaths in Japan. Some recent epidemiological studies have clarified that maternal lifestyles, such as smoking or drinking habits and passive smoking during pregnancy, provoke some congenital anomalies (Jones and Smith, 1973; Himmelberger et al., 1978; Ericson et al., 1979; Kuroki, 1988; Jacobson et al., 1993; Yuan et al., 1994), although there are negative reports (Borlee et al., 1978; Marbury et al., 1983; Pradat, 1992). However, to our knowledge, an association of anal atresia with smoking and/or drinking during pregnancy has not been previously reported. Our findings suggest that maternal drinking during early pregnancy elevated the risk of anal atresia, especially isolated anal atresia. Further studies are necessary to elucidate whether the increased risk of anal atresia is due to a teratogenic effect of alcohol or whether other confounding factors are present in combination with antenatal alcohol exposure.

A slightly increased trend was observed in the association of maternal smoking during pregnancy with isolated and syndromal anal atresia. It is important to analyze the combined and isolated effects of smoking and drinking habits on anal atresia. Further investigation is necessary to identify a dose effect of maternal drinking on infant anal atresia among their babies. 
In recent studies, passive smoking has been considered to posses same effects on the fetus as active smoking (Martin and Bracken, 1986; Mathai et al., 1992). Our results do not support the possibility that smoking by the husband, in the absence of maternal smoking and/or drinking during pregnancy, increases the risk of having infants with both groups of anal atresia. This can be explained by the fact that sample size is too small to explain the association, and the husbands may reduce smoking during pregnancy in this population.

Acknowledgments This work was supported in part by a grant from the Ministry of Health and Welfare of Japan.

\section{REFERENCES}

Anderson RC, Reed SC (1954): The likelihood of recurrence of congenital malformations. Lancet 74: $175-176$

Borlee I, Bouckaert A, Lechat MF, Misson CB (1978): Smoking patterns during pregnancy: weight, length and head circumference of progeny. Eur J Obstet Gynecol Reprod Biol 8: 171-177

Eriscon A, Kallen B, Westerholm P (1979): Cigarette smoking as an etiologic factor in cleft lip and palate. Am J Obstet Gynecol 135: 348-351

Himmelberger DU, Brown BW Jr, Cohen EN (1978): Cigarette smoking during pregnancy and the occurrence of spontaneous abortion and congenital abnormality. Am J Epidemiol 108: $470-479$

Jacobson JL, Jacobson SW, Sokol RJ, Martier SS, Ager JW, Kaplan-Estrin MG (1993): Teratogenic effects of alcohol on infant development. Alcohol Clin Exp Res 17: 174-183

Jones KL, Smith DW (1973): Pattern of malformation in offspring of chronic alcoholic women. Lancet 1: 1267-1271

Kuroki Y (1988): Monitoring of congenical anomalies. Congenital Anom 28 (Suppl.): S89-S99

Marbury MC, Linn S, Monson R, Schoenbaum DS, Stubblefield PG, Ryan KJ (1983): The association of alcohol consumption with outcome of pregnancy. Am J Public Health 73: 11651168

Martin TR, Bracken MB (1986): Association of low birth weight with passive smoke exposure in pregnancy. Am J Epidemiol 124: 633-642

Mathai M, Vijayasri R, Babu S, Jeyaseelan L (1992): Passive maternal smoking and birthweight in a south Indian population. Br J Obstet Gynecol 99 : 342-343

Nagashima M (1994): The likelihood of anorectal malformations. Jpn J Pediatr Surg 26: 353-358

Oeconomopoulos Ct (1961): Congenital anomalies of the rectum and anus. The technique of perineal proctoplasty. Am J Proctol 12: 363-373

Pradat P (1992): A case-control study of major congenital heart defects in Sweden-1981-1986. Eur J Epidemiol 8: 789-796

Saeki M, Akiyama H (1978): Anorectal malformations and heredity. Jpn J Pediatr Surg 10: 73-76

Schwoebel MG, Hirsig J, Schinzel A, Stauffer UG (1984): Familial incidence of congenital anomalies. J Pediatr Surg 19: 179-182

Stephens FD, Smith ED (1971): Ano-rectal malformation in children. Year Book Medical Publishers, Chicago

Weinstein ED (1965): Sex-linked imperforate anus. Pediatrics 35: 715-718

Yuan P, Wada N, Arai M, Okazaki I (1994): The association between maternal drinking and smoking and the risk of birth defects. Jpn J Public Health, 41: $751-758$ (in Japanese) 